\title{
Uso de diferentes fontes de proteína e de gordura na composição de proteinados para ovinos: consumo e digestibilidade aparente
}

\author{
Gilberto de Lima Macedo Junior ${ }^{1^{*}}$, Leonardo Lopes Magno, \\ Karla Alves Oliveira, Carolina Moreira Araújo, \\ Laura Ferrari Monteiro Varanis, Tamires Soares de Assis
}

\begin{abstract}
RESUMO
Objetivou-se neste artigo avaliar consumo e digestibilidade aparente por ovinos que consomem silagem de milho com diferentes proteinados. O trabalho foi conduzido na Fazenda Capim Branco, da Universidade Federal de Uberlândia. Foram utilizadas cinco ovelhas adultas, da raça Santa Inês, não gestantes, dispostas em delineamento quadrado latino $5 \mathrm{X} 5$. Os tratamentos consistiam em diferentes proteinados, possuindo como fonte proteica o farelo de soja protegido ou não, e a gordura protegida. Foi avaliado o consumo de matéria seca (MS), de proteína bruta (PB), de fibra em detergente neutro (FDN), de fibra em detergente ácido (FDA), de água e proteinado, e a digestibilidade referente à MS, à $\mathrm{PB}$ e à FDN. Os tratamentos não afetaram o consumo e a digestibilidade da matéria seca e dos nutrientes pelos animais $(\mathrm{P}>0,05)$, somente o consumo de água $(\mathrm{P}<0,05)$ foi alterado. A gordura protegida permitiu o suprimento energético sem causar queda do consumo, e o farelo de soja foi eficiente em atender as exigências dos animais. A utilização de proteinados foi eficiente na suplementação animal, sem alterar os dados referentes ao consumo e à digestibilidade da dieta.
\end{abstract}

Palavras-chave: energético, Ovis aries, proteico, suplementação.

\section{Introdução}

A produção de ruminantes possui grande destaque no cenário mundial, uma vez que visa atender a demanda da população por proteína de origem animal. Dessa forma, as práticas nutricionais utilizadas para os

\footnotetext{
${ }^{1}$ Faculdade de Medicina Veterinária da Universidade Federal de Uberlândia.

* Corresponding author: Campus Glória - Bloco 1CCG Sala 211A, BR-050, Km 78. Cep: 38410-337, Uberlândia, MG. Brazil. E-mail: gilbertomacedojr@gmail.com
} 
ruminantes são variadas em função das condições do sistema de produção, que, por sua vez, também apresenta variações devido à sazonalidade, ao solo, à disponibilidade de alimento, às exigências dos animais, entre outras. Ainda assim, a alimentação de ruminantes baseia-se, principalmente, na utilização de volumosos, sejam estes pastagens ou forragens na forma conservada.

Dentre as alternativas para atingir os objetivos produtivos, temos a utilização de produtos que atendam melhor às necessidades nutricionais. Assim, devem ser estabelecidas estratégias de suplementação que, aliadas ao correto manejo das pastagens, viabilizem, técnica e economicamente, os sistemas de produção animal (SILVA et al., 2009).

A utilização da suplementação proteica adequada destaca-se por proporcionar maior eficiência produtiva aos animais (ROCHA, 1999), uma vez que as exigências de nitrogênio não são supridas pelo alimento ou pela reciclagem endógena, podendo acarretar um quadro de deficiência proteica, ocorrendo limitação do crescimento microbiano (VALINOTE et al., 2005).

Portanto, a utilização de fontes proteicas na suplementação age como suprimento de nitrogênio e de enxofre para a microbiota ruminal, a qual depende dessa fonte para manter constante o fluxo de nutrientes (principalmente ácidos graxos voláteis e proteína microbiana), o que altera a taxa de passagem da digesta, fornecendo uma fonte adicional de aminoácidos para os tecidos (ALVES, et al., 2010). A proteína suplementar atua de forma direta pela correção do suprimento inadequado de aminoácidos totais ou essenciais. A resposta a essa suplementação é explicada pela mudança na digestibilidade da forragem e, também, pela eficiência metabólica da utilização de nutrientes (RUSSELL et al., 1992). O nutriente exigido em maior quantidade pelos ruminantes após a energia é a proteína, que tem como principal função fornecer os aminoácidos para a promoção dos muitos processos de síntese que ocorrem no organismo dos ruminantes (DUTRA et al., 1997), portanto é de grande importância que se 
mantenha o sincronismo entre a fermentação e a absorção das fontes energéticas e proteicas da dieta pelos micro-organismos ruminais.

Em sistemas de produção baseados apenas no fornecimento de volumosos, observa-se carência da suplementação de fontes lipídicas, pois a concentração desse nutriente em volumosos é baixa. Visando atender às necessidades energéticas dos animais, uma das formas seria adicionar tais fontes à dieta. Segundo Valinote et al. (2005), tal prática é uma alternativa para solucionar o déficit energético da dieta, podendo também melhorar a eficiência e o desempenho produtivo dos animais. Porém, em se tratando de lipídios para ruminantes, é fundamental considerar os efeitos de tal inclusão sobre a microbiota ruminal e consequentemente sobre o consumo e a digestibilidade.

Como maneira de evitar a ação da microbiota ruminal sobre a gordura e a proteína, tem-se como alternativa a utilização destas na forma protegida. A suplementação de proteína protegida, ou seja, de fontes que escapam da degradação ruminal e que complementam o perfil de aminoácidos da proteína microbiana, deverá melhorar o desempenho e a produção animal, além de reduzir a quantidade total de proteína exigida (MAIGA, SCHINGOETHE e HENSON, 1996; MATRAS, BARTLE e PRESTON, 1990). A extensão da melhoria causada pela suplementação com proteína protegida depende de sua qualidade, que deve atender às exigências dos animais (KLOPFENSTEIN, STOCK e BRITTON, 1985).

Objetivou-se com este trabalho avaliar o consumo e a digestibilidade aparente por ovinos que consomem silagem de milho e são suplementados com proteinados contendo diferentes fontes de gordura e de proteína.

\section{Material e métodos}

O presente estudo foi aprovado pela Comissão de Ética no Uso de Animais (Ceua) da Universidade Federal de Uberlândia (Protocolo $\mathrm{n}^{\mathrm{o}}$ 
133/14). O experimento foi conduzido na Fazenda Experimental Capim Branco, da Universidade Federal de Uberlândia - MG, entre os meses de outubro e dezembro de 2014. Foram utilizadas cinco ovelhas adultas, com peso médio de $50 \mathrm{~kg}$, da raça Santa Inês, não gestantes e alojadas em gaiolas metabólicas equipadas de comedouro, saleiro, piso ripado, acessório de separação de fezes e urina e bebedouro, em galpão de alvenaria coberto com telhas de barro.

As dietas fornecidas eram compostas de silagem de milho (matéria seca, 29,32 \%; proteína bruta, 7,83 \%; nutrientes digestíveis totais, 65,32 \%; e fibra em detergente neutro, 42,39 \%) juntamente com diferentes proteinados de alto consumo (100 a $170 \mathrm{~g} /$ dia, Tabela 1), compondo os respectivos tratamentos: farelo de soja + gordura protegida de palma (FS+GPP); farelo de soja (FS); farelo de soja protegido (FSP); farelo de soja protegido + gordura protegida de palma (FSP+GPP); e farelo de soja protegido + gordura protegida de soja (FSP+GPS). O fornecimento da dieta ocorreu duas vezes ao dia, às $8 \mathrm{~h}$ e posteriormente às $16 \mathrm{~h}$, com os valores ofertados definidos e mensuração posterior das sobras para obtenção dos valores de consumo.

Tabela 1. Composição centesimal (\%) dos proteinados.

\begin{tabular}{|c|c|c|c|c|c|}
\hline Ingredientes/Tratamentos & $\mathrm{FS}+\mathrm{GPP}$ & FS & FSP & $\mathrm{FSP}+\mathrm{GPP}$ & $\mathrm{FSP}+\mathrm{GPS}$ \\
\hline Farelo de milho & 10 & 15 & 15 & 10 & 10 \\
\hline Farelo de soja & 5 & 10 & - & - & - \\
\hline Farelo de soja protegido & - & - & 10 & 5 & 5 \\
\hline Polpa cítrica & 10 & 10 & 10 & 10 & 10 \\
\hline Gordura de soja & - & - & - & - & 10 \\
\hline Gordura de palma & 10 & - & - & 10 & - \\
\hline Sal mineral & 30 & 30 & 30 & 30 & 30 \\
\hline Sal branco & 30 & 30 & 30 & 30 & 30 \\
\hline Ureia & 5 & 5 & 5 & 5 & 5 \\
\hline
\end{tabular}

Tratamentos: FS+GPP = farelo de soja + gordura protegida de palma; FS = farelo de soja; FSP = farelo de soja protegido; FSP+GPP = farelo de soja protegido + gordura protegida de palma; FSP+GPS = farelo de soja protegido + gordura protegida de soja. 
O experimento foi dividido em cinco fases de 15 dias cada, sendo que dentro de cada fase os dez primeiros dias referiam-se à adaptação do animal à dieta, e os cinco dias posteriores à coleta de sobras (alimento e água), fezes e urina para avaliação da digestibilidade. Os animais foram pesados no início e no final de cada período de coleta, para cálculo do consumo de alimento em relação ao peso corporal e obtenção do peso médio.

A água foi fornecida todos os dias no período da manhã, com quantidade estabelecida de seis litros para cada animal, sendo as sobras mensuradas no dia posterior para obtenção dos dados de consumo de água.

A oferta do proteinado foi em quantidade preestabelecida de 150 g/animal/dia. As sobras foram mensuradas para estimar o consumo, e sempre que os valores referentes a elas foi zero, aumentou-se a quantidade fornecida em $10 \%$ até atingir sobra equivalente a $10 \%$ do ofertado.

As fezes na matéria natural foram pesadas diariamente em balança com precisão de 5 g. Foi avaliado também o escore fecal, de acordo com escala proposta por Gomes (2008), sendo que na escala um (1) as fezes são ressecadas e sem brilho; na escala dois (2), normais; na escala três (3), ligeiramente amolecidas; na escala quatro (4), amolecidas, perdendo o formato e coladas umas às outras (cacho de uva); na escala cinco (5), amolecidas e sem formato normal (fezes de suínos); e na escala seis (6), , diarreicas.

Todos os dias foram colhidas amostras de sobras e fezes de cada animal; ao final do período de colheita, elas eram homogeneizadas e formada uma amostra composta, para posteriores análises bromatológicas e cálculo do consumo e da digestibilidade da matéria seca e dos nutrientes. Após o final do período de coleta, essas amostras eram armazenadas em freezers horizontais a $-15{ }^{\circ} \mathrm{C}$, para conservação dos nutrientes. Posteriormente foi feita a pré-secagem das amostras em estufa de circulação forçada de ar, a 55 ${ }^{\circ} \mathrm{C}$ por 72 horas, até se obter peso constante. Feito isso, as amostras foram trituradas em moinho de facas do tipo Willey, em partículas de $1 \mathrm{~mm}$. Logo 
após, foram levadas ao laboratório onde foi feita determinação da matéria seca das amostras de sobras e fezes, em estufa a $105^{\circ} \mathrm{C}$ por 24 horas, sendo possível calcular sua matéria seca definitiva.

Após determinação da matéria seca definitiva das amostras de sobras e do ofertado da dieta e das fezes, estas foram submetidas a análises laboratoriais para obtenção dos dados referentes à matéria seca (MS), à proteína bruta $(\mathrm{PB})$, à fibra em detergente neutro (FDN), à fibra em detergente ácido (FDA) e à matéria mineral (MM). Todas as análises foram executadas de acordo com a metodologia descrita por Silva e Queiroz (2002). A realização das análises ocorreu no Laboratório de Análises de MatériaPrima e Rações da Faculdade de Medicina Veterinária da Universidade Federal de Uberlândia.

Após análises laboratoriais, foram realizados os cálculos de consumo da matéria seca (CMS), da proteína bruta (CPB), da fibra em detergente neutro (CFDN) e da fibra em detergente ácido (CFDA). Os valores referentes ao consumo foram obtidos pela diferença do ofertado em relação às sobras. Também foram realizados os cálculos referentes à digestibilidade da matéria seca (DMS), à digestibilidade da proteína bruta (DPB) e à digestibilidade da fibra em detergente neutro (DFDN), pela fórmula proposta por Merchen (1988):

$$
\mathrm{DA}=\frac{\text { Nutriente ingerido }- \text { Nutriente excretado nas fezes x } 100}{\text { Nutriente ingerido }}
$$

Em que:

DA: digestibilidade aparente

$\mathrm{O}$ experimento foi delineado em quadrado latino $5 \mathrm{x} 5$, sendo cinco tratamentos, cinco períodos e cinco unidades experimentais. Os dados foram submetidos à análise estatística através do teste SNK (Student-NewmanKeuls), com significância de $5 \%$. 


\section{Resultados e discussão}

Na Tabela 2, encontram-se os dados de consumo de matéria seca (CMS) em gramas por dia em relação ao peso vivo animal (CMS/PV) e ao peso metabólico animal (CMS/PM) do consumo de proteinado (Cprot), e a relação entre o CMS e o Cprot (CMS/Cprot), sendo que não se observou diferença $(\mathrm{P}>0,05)$ entre os tratamentos para nenhuma das variáveis analisadas.

Tabela 2. Consumo de matéria seca (CMS), relação entre consumo de matéria seca e peso vivo (CMS/PV) e peso metabólico (CMS/PM), consumo de proteinado (Cprot) e relação entre consumo de matéria seca e consumo de proteinado (CMS/Cprot) dos animais submetidos aos tratamentos experimentais.

\begin{tabular}{lccccc}
\hline TRATAMENTO & $\begin{array}{c}\text { CMS } \\
(\mathrm{g} / \mathrm{dia})\end{array}$ & $\begin{array}{c}\text { CMS/PV } \\
(\%)\end{array}$ & $\begin{array}{c}\text { CMS/PM } \\
\left(\mathrm{g} / \mathrm{kg}^{0}, 75\right.\end{array}$ & $\begin{array}{c}\text { Cprot } \\
(\mathrm{g} / \mathrm{dia})\end{array}$ & $\begin{array}{c}\text { CMS/Cprot } \\
(\mathrm{g} / \text { dia })\end{array}$ \\
\hline FS+GPP & 1099,52 & 2,13 & 57,11 & 113 & 11,24 \\
FS & 1051,55 & 2,04 & 54,59 & 108 & 14,12 \\
FSP & 1018,09 & 1,98 & 53,07 & 116,2 & 9,81 \\
FSP+GPP & 1097,28 & 2,1 & 56,6 & 127,4 & 10,08 \\
FSP+GPS & 1088,41 & 2,08 & 56,04 & 86,6 & 13,54 \\
\hline Média Geral & 1070,97 & 2,07 & 55,48 & 110,36 & 11,76 \\
CV (\%) & 8,92 & 7,35 & 7,64 & 26,04 & 38,49 \\
\hline
\end{tabular}

Tratamentos: FS+GPP = farelo de soja + gordura protegida de palma; FS = farelo de soja; $\mathrm{FSP}=$ farelo de soja protegido; FSP+GPP = farelo de soja protegido + gordura protegida de palma; FSP+GPS = farelo de soja protegido + gordura protegida de soja; CV = coeficiente de variação.

Os animais apresentaram CMS médio de 1070,97 g/animal/dia, o equivalente a aproximadamente $2,2 \%$ do peso vivo, mostrando que este se manteve próximo dos valores recomendados pelo NRC (2007), que deve ser de 2,0 \% para essa categoria, concluindo que ele não foi influenciado pelos diferentes tipos de proteinado. A semelhança no CMS pode ter sido causada pelo fato de a base da dieta fornecida ser a mesma, alterando apenas o proteinado ofertado, e devido aos animais serem da mesma categoria em relação a peso, idade e estado fisiológico. 
O Cprot e a relação CMS/Cprot também não diferiram entre os tratamentos utilizados, o que pode ser explicado pelo fato de os animais consumirem o suplemento visando ao atendimento da necessidade nutricional - uma vez que foi estabelecida a oferta de $150 \mathrm{~g} /$ dia por animal , e também devido ao suprimento das exigências dos animais de acordo com a relação de proteína com os níveis de carboidratos na dieta. Destaca-se que apenas o tratamento FSP+GPS consumiu abaixo de $100 \mathrm{~g} / \mathrm{dia}$.

Em se tratando de digestibilidade ruminal, a disponibilidade de carboidratos no órgão possui efeitos diretos sobre a utilização de compostos nitrogenados, visto que a microbiota suprirá sua demanda energética através da fermentação destes, o que influenciará diretamente no processo de síntese de proteína microbiana (POPPI e MCLENNAN, 1995). A adição de carboidratos através do volumoso, no caso a silagem de milho, também promoverá economia no gasto de aminoácidos, visto que quando o fornecimento de carboidratos é um fator limitante, há a utilização de aminoácidos como fonte de energia (PEREIRA et al., 2005; SILVA et al., 2007).

O farelo de soja neste trabalho foi utilizado de duas formas: não protegida (nos tratamentos (FS+GPP e FS) e protegida (nos tratamentos FSP, FSP+GPP e FSP+GPS), levando em consideração que o farelo na forma não protegida terá parte da sua digestão realizada no rúmen pela microbiota, que utilizará esse componente como forma de energia e suprimento de nitrogênio, promovendo assim seu desenvolvimento e, consequentemente, maior síntese e fornecimento de proteína microbiana ao animal. Por outro lado, o farelo na forma protegida terá a digestão realizada basicamente no intestino delgado, com a utilização dos aminoácidos destedo mesmo diretamente pelo animal. Assim sendo, ambas as formas de apresentação do farelo de soja, quando fornecidas com a silagem de milho visando ao suprimento proteico, foram eficientes, uma vez que não houve diferenças relacionadas ao Cprot e ao CMS. 
$\mathrm{O}$ consumo de água $\left(\mathrm{CH}_{2} \mathrm{O}\right)$ pelos animais do tratamento FSP+GPP (Tabela 3) foi maior $(\mathrm{P}<0,05)$, provavelmente por uma possível alteração no fluxo digestivo, com maior formação de substratos no intestino delgado, visto que ambas as forma do farelo estavam na forma protegida, podendo ter ocasionado maior demanda de água para o equilíbrio da digestão, fato evidenciado pela ausência de acréscimo do volume urinado (Tabela 3) em relação aos outros tratamentos, intensificando a possibilidade de maior demanda de água no processo digestivo. A digestão proteica no intestino delgado apresenta maior produção de calor em relação aos demais nutrientes, fato que possivelmente aumentou o consumo hídrico. Destaca-se também que esse tratamento teve o maior consumo numérico (sem significância estatística) de proteinado (Tabela 2), podendo ter elevado o consumo de água.

Tabela 3. Consumo de água $\left(\mathrm{CH}_{2} \mathrm{O}\right)$, relação entre o consumo de água e o consumo de matéria seca $\left(\mathrm{CH}_{2} \mathrm{O} / \mathrm{CMS}\right)$, volume de urina e escore fecal em função dos tratamentos.

\begin{tabular}{lcccc}
\hline TRATAMENTO & $\begin{array}{c}\mathrm{CH}_{2} \mathrm{O} \\
(\mathrm{L} / \mathrm{dia})\end{array}$ & $\begin{array}{c}\mathrm{CH} 2 \mathrm{O} / \mathrm{CMS} \\
(\mathrm{L} / \mathrm{kg})\end{array}$ & $\begin{array}{c}\text { Volume de Urina } \\
(\mathrm{L} / \text { dia })\end{array}$ & Escore Fecal* $^{*}$ \\
\hline FS+GPP & $1,74 \mathrm{ab}$ & $1,63 \mathrm{a}$ & 1,04 & 2,80 \\
FS & $1,68 \mathrm{ab}$ & $1,53 \mathrm{ab}$ & 1,06 & 2,08 \\
FSP & $1,55 \mathrm{ab}$ & $1,52 \mathrm{ab}$ & 0,93 & 2,08 \\
FSP+GPP & $1,93 \mathrm{a}$ & $1,83 \mathrm{a}$ & 1,13 & 3,00 \\
FSP+GPS & $1,33 \mathrm{~b}$ & $1,18 \mathrm{~b}$ & 0,84 & 2,60 \\
\hline Média geral & 1,65 & 1,54 & 1,00 & 2,80 \\
CV & 13,96 & 14,91 & & $\mathrm{xxx}$ \\
\hline
\end{tabular}

Tratamentos: FS+GPP = farelo de soja + gordura protegida de palma; $\mathrm{FS}$ = farelo de soja; $\mathrm{FSP}=$ farelo de soja protegido; FSP+GPP = farelo de soja protegido + gordura protegida de palma; FSP+GPS = farelo de soja protegido + gordura protegida de soja; CV = coeficiente de variação; Valores seguidos de letras distintas na mesma coluna diferem entre si estatisticamente a $5 \%$ pelo teste SNK. *Estatística não paramétrica.

Quanto à relação entre $\mathrm{CH}_{2} \mathrm{O} / \mathrm{CMS}$ e os tratamentos $\mathrm{FS}+\mathrm{GPP}$ e FSP+GPP, esta apresentou maior demanda de água por quilo de matéria seca consumida. Tal fato deve-se provavelmente à presença da gordura de palma protegida em ambos os tratamentos, a qual será absorvida na forma de ácidos graxos no intestino delgado, com a necessidade, antes, de passar 
pelos processos de solubilização no meio aquoso do órgão, sendo então necessária maior quantidade de água para que se finalize o processo de digestão. Além disso, as inferências feitas no consumo de água também se aplicam a essa variável.

De modo geral, o consumo de água foi de acordo com o recomendado pelo NRC (2007), que sugere para cálculo do consumo basal de água a seguinte fórmula: $\mathrm{CH}_{2} \mathrm{O}=3,86 \times \mathrm{CMS}-0,99$. Diante disso, com um CMS médio de 1.070,97 g/animal/ dia (Tabela 2), tem-se que o consumo de água ideal seria superior a 4,0 L/animal/dia. Porém, ao considerar que o alimento ingerido possui aproximadamente $70 \%$ de água na composição, tem-se um consumo de aproximadamente 2,5 litros de água ingeridos através da dieta, valor que, agregado ao consumo de água, aproxima-se do indicado.

De acordo com a escala proposta por Gomes (2008), o escore fecal normal é 2, logo os valores encontrados neste experimento encontram-se dentro da normalidade. E, também, a não diferença encontrada entre os tratamentos evidencia que não houve alteração quanto à excreção das fezes em relação à textura, ao formato e ao teor de umidade, mesmo com a inclusão de ingredientes protegidos ou não protegidos no proteinado.

O consumo da proteína bruta (CPB) e os consumos de fibra em detergente ácido (CFDA) e de fibra em detergente neutro (CFDN, Tabela 4) mantiveram-se com resultados numéricos semelhantes, independentemente do tratamento experimental aplicado, tendo como uma das possíveis explicações o fato de que a quantidade e o tipo de volumoso ofertado foram os mesmos. Segundo Van Soest (1965), o consumo de matéria seca está diretamente ligado ao teor de FDN na dieta. Moreira et al. (2001), utilizando silagem de milho na dieta de ovinos, encontraram valores referentes à ingestão de matéria seca igual a 752,63 g/animal/dia, sendo esse valor consideravelmente mais baixo que o do presente trabalho, que apresentou ingestão média de matéria seca igual a 1070,97 g/animal/dia (Tabela 2). Quanto aos valores referentes à FDN encontrados por Moreira et al. (2001), 
estes foram proporcionalmente superiores, tendo sido encontrado consumo de FDN igual a 447,88 g/animal/dia, e no presente trabalho valor de consumo médio de FDN de 589,81 g/animal/dia (Tabela 4). Segundo Macedo Júnior et al. (2007), o alimento com fibra de baixa qualidade pode afetar negativamente o CMS, assim como a digestibilidade. O volumoso ofertado neste experimento tinha boa qualidade, o que possivelmente foi um dos fatores para a igualdade no consumo de matéria seca (Tabela 2) e no consumo de fibra em detergente neutro (Tabela 4).

Tabela 4. Consumo de fibra em detergente neutro (CFDN), relação entre consumo de FDN e peso vivo (CFDN/PV), relação entre consumo de FDN e consumo de proteinados (CFDN/Cprot), consumo de fibra em detergente ácido (CFDA) e consumo de proteína bruta $(\mathrm{CPB})$ referentes a cada tratamento experimental.

\begin{tabular}{lccccc}
\hline TRATAMENTO & $\begin{array}{c}\text { CFDN } \\
(\mathrm{g} / \mathrm{dia})\end{array}$ & $\begin{array}{c}\text { CFDN/PV } \\
(\%)\end{array}$ & $\begin{array}{c}\text { CFDN/Cprot } \\
(\mathrm{g} / \mathrm{dia})\end{array}$ & $\begin{array}{c}\text { CFDA } \\
\text { (g/dia) }\end{array}$ & $\begin{array}{c}\text { CPB } \\
(\mathrm{g} / \mathrm{dia})\end{array}$ \\
\hline FS+GPP & 605,64 & 1,82 & 6,19 & 361,42 & 85,12 \\
FS & 587,32 & 1,78 & 8,13 & 344,11 & 80,8 \\
FSP & 555,43 & 1,83 & 5,41 & 326,74 & 76,07 \\
FSP+GPP & 602,47 & 1,83 & 5,62 & 355,32 & 85,12 \\
FSP+GPS & 598,21 & 1,81 & 7,46 & 350,78 & 85,6 \\
\hline Média Geral & 589,81 & 1,82 & 6,56 & 347,67 & 82,48 \\
CV (\%) & 9,65 & 2,69 & 42,27 & 9,19 & 10,64 \\
\hline
\end{tabular}

Tratamentos: FS+GPP = farelo de soja + gordura protegida de palma; $\mathrm{FS}=$ farelo de soja; $\mathrm{FSP}=$ farelo de soja protegido; FSP+GPP = farelo de soja protegido + gordura protegida de palma; FSP+GPS = farelo de soja protegido + gordura protegida de soja; $\mathrm{CV}=$ coeficiente de variação.

Pereira et al. (2005), testando silagem de milho com adição de polpa cítrica à dieta de ovinos, verificou, ao utilizar silagem de milho sem inclusão do produto testado, que a ingestão de FDN/PV foi igual a 1,84 \%, justificando, com base nesse valor, que o controle do consumo ocorreu provavelmente devido ao enchimento gástrico, o que pode também ter ocorrido no presente trabalho, que constatou valor semelhante, de 1,82\%.

Os microrganismos ruminais dependem de fontes de energia e de nitrogênio fermentáveis para sua atividade metabólica, influenciando fortemente a digestibilidade ruminal e, consequentemente, o fluxo de 
nutrientes, tanto de ácidos graxos voláteis quanto de proteína microbiana para o ruminante. Portanto, a sincronização da fermentação energética e da degradação da PB é essencial para uma eficiente utilização da energia e da proteína pelos microrganismos ruminais (EKINCI e BRODERICK, 1997; ALVES et al., 2010). Logo, pode-se inferir que os diferentes tipos de proteinado utilizados foram capazes de estabelecer esse sincronismo entre a fermentação energética e a proteica, visto que não foi observada diferença entre os tratamentos.

Não houve diferença entre os tratamentos para as digestibilidades da matéria seca (DMS), da proteína bruta (DPB) e da fibra em detergente neutro (DFDN, Tabela 5). Com relação à similaridade entre os resultados dos diferentes tratamentos, sabe-se que o farelo de soja possui alta porcentagem de proteína degradável no rúmen (PDR) e, quando tal ingrediente é submetido a processos químicos visando protegê-lo da ação da microbiota ruminal, a digestão e a absorção ocorrerão no intestino delgado, permitindo que todo esse produto seja destinado diretamente ao animal, explicando a igualdade entre as DMS, as DPB e as DFDN. Cabral et al. (2001) puderam verificar, ao comparar farelo de soja com outras fontes proteicas na dieta de bovinos, que o farelo foi um dos que apresentaram melhores resultados quando se tratando de digestibilidade intestinal. Tal fato também pode ter influenciado na similaridade dos valores referentes a escore fecal (Tabela 3). 
Tabela 5. Digestibilidade da matéria seca (DMS), da proteína bruta (DPB) e da fibra em detergente neutro (DFDN) referentes a cada tratamento experimental.

\begin{tabular}{lccc}
\hline Tratamento & DMS (\%) & DPB (\%) & DFDN (\%) \\
\hline FS+GPP & 58,49 & 44,02 & 51,67 \\
FS & 59,06 & 42,9 & 53,98 \\
FSP & 53,77 & 42,49 & 47,73 \\
FSP+GPP & 58,98 & 46,48 & 53,40 \\
FSP+GPS & 63,05 & 51,13 & 56,77 \\
\hline Média Geral & 58,67 & 45,40 & 52,71 \\
\hline CV (\%) & 16,11 & 27,3 & 19,54 \\
\hline
\end{tabular}

Tratamentos: FS+GPP = farelo de soja + gordura protegida de palma; FS = farelo de soja; FSP = farelo de soja protegido; FSP+GPP = farelo de soja protegido + gordura protegida de palma; FSP+GPS = farelo de soja protegido + gordura protegida de soja; $\mathrm{CV}$ = coeficiente de variação.

Como a adição lipídica nos tratamentos ocorreu na forma de gordura protegida, a qual possui a digestão realizada no intestino delgado, os efeitos negativos sobre a digestibilidade da fibra podem ter sido amenizados, não interferindo no consumo de matéria seca, já que o fluxo ruminal provavelmente manteve-se estável. Dias et al. (2000), testando a adição de diferentes níveis de concentrado na dieta de ruminantes, também não encontraram diferenças entre os tratamentos, com uma média de 57,48 \% de DMS, valor próximo ao encontrado neste trabalho, de 58,67\%, podendo ser justificado pelo consumo semelhante de proteinado pelos animais de todos os tratamentos. Cabral et al. (2001), alimentando bovinos com forragens tropicais, justificaram a DMS com valores aproximados aos do presente trabalho, devido aos índices de carboidratos não fibrosos na silagem de milho.

Segundo Macedo Júnior et al. (2007), em dietas com baixa densidade energética, o consumo será limitado pelo enchimento físico e não pela saciedade sobre a demanda nutricional do animal. Com a adição da gordura protegida, a dieta terá o valor energético elevado, atendendo às exigências dos animais, porém sem influência negativa da adição de altos teores lipídicos, já que tal prática é utilizada visando atender à demanda energética na dieta. 
Pôde-se constatar, neste artigo, que a dieta contendo gordura na forma protegida não alterou a digestibilidade ruminal, visto que não houve alterações nos valores de CMS (Tabela 2) em nenhum dos tratamentos, notando similaridade na digestão ruminal tanto nos tratamentos com gordura protegida quanto nos que não a utilizaram, provavelmente porque a digestão da gordura ocorreu no intestino delgado.

A igualdade observada no consumo e na digestibilidade da fração fibrosa das dietas experimentais pode se dar em razão da similaridade do teor de fibra de cada tratamento, e do fato de tanto a gordura protegida quanto a adição de farelo de soja, protegido ou não, não terem ocasionado distúrbios digestivos, ocorrendo a maior parte da liberação lipídica no intestino delgado, sem influência negativa sobre a microbiota ruminal.

\title{
Conclusão
}

A utilização de proteinados com diferentes fontes de proteína e de gordura, protegidas ou não, não prejudica o consumo de matéria seca pelos animais, podendo ser fornecidos com a silagem de milho. A escolha do proteinado deve ser feita com base nos fatores produtivos e econômicos que melhor atendam ao sistema de produção.

\section{Use of different protein and fat sources in the composition of protein-based products for sheep: intake and apparent digestibility}

\begin{abstract}
The objective was to evaluate the intake and the apparent digestibility of sheep, consuming corn silage with different protein concentrates. The work was conducted at Fazenda Capim Branco, Federal University of Uberlândia. Five adult, non-pregnant Santa Ines sheep were used, arranged in a 5X5 latin square outline. The treatments consisted of different protein concentrates, having as protein source soybean meal protected or not, and presence of protected fat. The dry matter (DM), crude protein (CP), neutral detergent fiber (NDF), acid detergent fiber (ADF), water and protein concentrate intake, and DM, CP and NDF digestibilities were evaluated. The treatments did not affect the intake and digestibility of dry matter and nutrients by the animals ( $\mathrm{P}>0.05)$, and only water
\end{abstract}


consumption $(\mathrm{P}<0.05)$ was altered. The protected fat allowed the energetic supply without causing intake drop and the soybean meal, was efficient in meeting the requirements of the animals. The use of protein concentrates was efficient in animal supplementation without altering the data regarding diet intake and digestibility.

Keywords: energetic, Ovis aries, protein, supplementation

\section{Referências}

ALVES, E. M.; PEDREIRA, M. S.; OLIVEIRA, C. A. S.; FERREIRA, D. N.; MOREIRA, B. S.; FREIRE, L. D. R. Importância da sincronização do complexo proteína/energia na alimentação de ruminantes. Publicações em Medicina Veterinária e Zootecnia - PUBVET, Londrina, v. 4, n. 20, ed. 125, art. 845, 2010 .

CABRAL, L. S.; VALADARES FILHO, S. C.; MALAFAIA, P. A. M.; LANA, R. P.; SILVA, J. F. C.; VIEIRA, R. A. M.; PEREIRA, E. S. Estimação da digestibilidade intestinal da proteína de alimentos por intermédio da técnica de três estádios. Revista Brasileira de Zootecnia, v. 30, n. 2, p. 546-552, 2001.

DIAS, H. L. C.; VAlaDARES FILHO, S. C.; SILVA, J. F. C.; PAULINO, M. F.; CECON, P. P.; LEÃO, M. I.; OLIVEIRA, R. V. Consumo e Digestões Totais e Parciais em Novilhos F1 Limousin x Nelore Alimentados com Dietas contendo Cinco Níveis de Concentrado. Revista Brasileira de Zootecnia, v. 29, n. 2, p. $545-554,2000$.

DUTRA, A. R.; QUEIROZ, A. C.; PEREIRA, J. C.; VALADARES FILHO, S. C.; THIEBAUT, J. T. L.; MATOS, F. N.; RIBEIRO, C. V. M. Efeitos dos níveis de fibra e das fontes de proteínas sobre a síntese de compostos nitrogenados microbianos em novilhos. Revista Brasileira de Zootenia, v. 26, n. 4, p. 797-805, 1997.

EKINCI, C.; BRODERICK, G. A. Effect of processing high moisture ear corn on ruminal fermentation and milk yield. Journal of Dairy Science, v. 80, p. 32983307, 1997. 
GOMES, S. P. Tamanho de partícula do volumoso e frequência de alimentação sobre aspectos nutricionais e do metabolismo energético em ovinos. 2008, 83 f. Tese de Doutorado em Escola de Veterinária - Universidade Federal de Minas Gerais, Belo Horizonte, 2008.

KLOPFENSTEIN, T.; STOCK, R.; BRITTON, R. (1985). Relevance of Bypass Protein to Cattle Feeding. The Professional Animal Scientist, v. 1, n. 1, p. 27 31,1985 .

MACEDO JÚNIOR, G. L.; ZANINE, A. M.; BORGES, I.; PÉREZ, J. R. O. Qualidade da fibra para a dieta de ruminantes. Ciência Animal, v. 17, n. 2, p. 7 18, 2007.

MAIGA, H. A.; SCHINGOETHE, D. J.; HENSON, J. E. Ruminal degradation, amino acid composition and intestinal digestibility of the residual components of five protein supplements. Journal of Dairy Science, v. 79, n. 9, p. 1647-1653, 1996.

MATRAS, J.; BARTLE, S. J.; PRESTON, R. L. Effects of ruminal escape proteins and canola meal on nitrogen utilization by growing lambs. Journal of Animal Science, v. 68, n. 1, p. 2549-2554, 1990.

MERCHEN, N. R. Digestión, absorción y excreción en los rumiantes. In: CHURCH, D.C. El rumiante. Fisiología digestiva y nutrición. Zaragoza: Acríbia. Cap.9. 1988.

MOREIRA, A. L; PEREIRA, O. G.; GARCIA, R.; VALADARES FILHO, S. C.; CAMPOS, J. M. S.; MORAES, S. A.; ZERVOUDAKIS, J. T. Consumo e Digestibilidade Aparente dos Nutrientes da Silagem de Milho e dos Fenos de Alfafa e de Capim-Coastcross, em Ovinos. Revista Brasileira de Zootecnia, v. 30, n. 3, p. 1099-1105, 2001. 
NACIONAL RESEARCH COUNCIL - NRC. Nutrient requirements of small ruminants: Sheep, goats, cervids, and new world camelids. Washington, D. C.: National Academy Press, 2007. 384 p.

PEREIRA, E. S.; ARRUDA, A. M. V.; MIRANDA, L. F.; MIZUBUTI, I. Y.; MUNIZ, E. B.; PINTO, A. P. Importância da inter-relação carboidrato e proteína em dietas de ruminantes. Ciências Agrárias, v. 26, n. 1, p. 125-134, 2005.

POPPI, D. P.; MCLENNAN, S. R. Protein and energy utilization by ruminants at pasture. Journal of Animal Science, v. 73, n. 1, p. 278-290, 1995.

ROCHA, M. G. Suplementação a campo de bovinos de corte. In: Lobato, J.F.(Ed). Produção de bovinos de corte. Porto Alegre: PUCRS. 1999.

RUSSELL, J. B.; O’CONNOR, J. D.; FOX, D. G.; VAN SOEST, P. J.; SNIFFEN, C. J. A net carbohydrate and protein system for evaluating cattle diets. 1. Ruminal fermentation. Journal of Animal Science, v. 70, n. 11, p. 3551-3561, 1992.

SILVA, D. J.; QUEIROZ, A. C. Análises de alimentos (métodos químicos e biológicos). 3.ed. Viçosa, MG: Editora UFV. 2002.

SILVA, M. M. C.; RODRIGUES, M. T.; BRANCO, R. H.; RODRIGUES, C. A. F.; SARMENTO, J. L. R.; QUEIROZ, A. C.; SILVA, S. P. Suplementação de lipídios em dietas para cabras em lactação:consumo e eficiência de utilização de nutrientes. Revista Brasileira de Zootecnia, v. 36, n. 1, p. 257-267, 2007.

SILVA, F. F.; SÁ, J. F.; SCHIO, A. R.; ÍTAVO, L. C. V.; SILVA, R. R.; \& MATEUS, R. G. Suplementação a pasto: disponibilidade e qualidade $\mathrm{x}$ níveis de suplementação x desempenho. Revista Brasileira de Zootecnia, v. 38, n. 1, p. 371-389, 2009.

VAlinote, A. C.; NOGUEIRA FILHO, J. C. M.; LEME, P. R.; SILVA, S. L.; CUNHA, J. A. Fontes de Lipídeos e Monensina na Alimentação de Novilhos Nelore 
e sua Relação com a População de Protozoários Ciliados do Rúmen. Revista Brasileira de Zotecnia, v. 34, n. 4, p. 1418-1423, 2005.

VAN SOEST, P. J. Symposium on factors influencing the voluntary intake of herbage by ruminants: voluntary intake in relation to chemical composition and digestibility. Journal of Animal Science, v. 24, n. 3, p. 834-843, 1965. 